\title{
Evaluation of Maxillary Sinus Dimensions Using Cone Beam Computed Tomography in Egyptian Population
}

\author{
Hitham T Hamdy ${ }^{* 1}$, Assem M Kamel ${ }^{2}$, Fathy A Abo Zaid ${ }^{2}$
}

Codex : 11/2021/10

Aadj@azhar.edu.eg

\section{KEYWORDS}

Maxillary sinus, $C B C T$,

Sexual dimorphism, Population, radiographic sections.

1. Department of Oral \& Maxillofacial Radiology, Faculty of Dental Medicine,Aswan University, Egypt.

2. Department of Oral Medicine, Periodontology, Diagnosis and Oral Radiology, Faculty of Dental Medicine, Al-Azhar University, Assist, Egypt.

* Corresponding Author e-mail: Hithamtawfik.2046@azhar.edu.eg

\begin{abstract}
Aim: This study was designed to evaluate the possible variation in dimensions of maxillary sinuses in Egyptian population using CBCT. Subjects and Methods: 120 CBCT of bilaterally maxillary sinuses of adult Egyptians of both sexes with ages ranging from 20 to 50 years were randomly selected. Then CBCT images were grouped according to gender, age and side. Three measurements in millimeters (width, depth, height), were taken on the axial and coronal cross sections. Results: Right and left height was statistically significant difference in male group than in female group $(\mathrm{P}<0.005)$. There was not statistically significant difference in dimensions between any age group and any another age group. It was difference between right and left sides of maxillary sinus, but this difference was not statistically significant. Conclusion: mean values of maxillary sinuses dimensions of males were found to be larger than these of females and this difference was statistically significant only for height dimensions.
\end{abstract}

\section{INTRODUCTION}

Maxillary sinus is a pneumatic space with its base adjacent to the nasal wall and apex pointing to the zygoma. It is the largest bilateral air sinus located in the body of the maxilla and opens in the middle nasal meatus of the nasal cavity with single or multiple openings. It varies greatly in size, shape, and position not only in different individuals ${ }^{(1)}$

Maxillary sinus is located in the left and right maxillary bones and consists of two air filled cavities lined with mucosa. Maxillary sinus tends to appear at the end of the second embryonic month and complete by the age of 18 to 20 years. The primary components of any skeletal analysis in forensic sciences are age and sex determination. ${ }^{(2)}$

Considering the complex structure of maxillary sinus, diagnostic methods like magnetic resonance imaging (MRI) and computed tomography (CT) are used as gold standard to evaluate the true anatomy of sinuses. ${ }^{(3)}$ 
In addition, cone beam computed tomography provides high resolution images in three dimensions with low radiation dose. Accuracy of the studies evaluates anatomic structures of the maxillofacial region progress with the development of cone beam computed tomography systems. ${ }^{(4)}$

\section{METHODOLOGY}

The present study was performed as a retrospective analysis of $120 \mathrm{CBCT}$ images of bilaterally maxillary sinuses of adult Egyptians of both sexes. Images were randomly selected from oral radiology department at faculty of dentistry of Minia University, South Valley University and other private radiographic centers.

\section{Inclusion criteria:}

1. Images of patient were including posterior teeth in both sides in all CBCT images.

2. Images were covered the entire extent of the sinus with all boundaries. ${ }^{(5)}$

\section{Exclusion criteria}

1. Images not covered the entire extent of the sinus. ${ }^{(1)}$

2- Images with existing sinus pneumatization or sinus augmentation or other kinds of maxillary sinus surgery. ${ }^{(6)}$

\section{Grouping of CBCT Images:}

\section{According to gender:}

Group A: sixty CBCT images of male patients.

Group B: sixty CBCT images of female patients.

\section{According to age:}

Group 1: forty CBCT images aged from 20 years to 30 years

Group 2: forty CBCT images aged from 30 to 40 years
Group 3: forty CBCT images aged from 40 to 50 years

\section{According to side:}

Group I: 120 CBCT images of right side

Group II: 120 CBCT images of Left side

\section{Radiographic evaluation of maxillary sinus:}

The collected CBCT images were extracted from its capturing software and imported as (DICOM) to image reconstruction. Two independent observers (used these DICOM files and entered it in Blue sky bio software viewer for measuring dimensions of maxillary sinus in millimeters. ${ }^{(5)}$

\section{The depth in millimeters was measured as :}

The longest distance from the most anterior point to the most posterior point of the medial wall in the axial view as showing in (figure 1: A).

\section{The width in millimeters was measured as :}

The longest distance perpendicular from the medial wall of the sinus to the most lateral wall of the lateral process of the maxillary sinus in the axial view as showing in (figure1: B).

\section{The height in millimeters was measured as:}

The longest distance from the lowest point of the sinus floor to the highest point of the sinus roof in the coronal view ${ }^{(7)}$ as showing in (figure1:C).

\section{Statistical Analysis:}

The data were collected, tabulated and statistically analyzed

\section{RESULTS}

Right and left height was statistically significant difference in mean values of dimensions of male group than in female group $(\mathrm{P}<0.005)$. There was not statistically significant difference in mean 

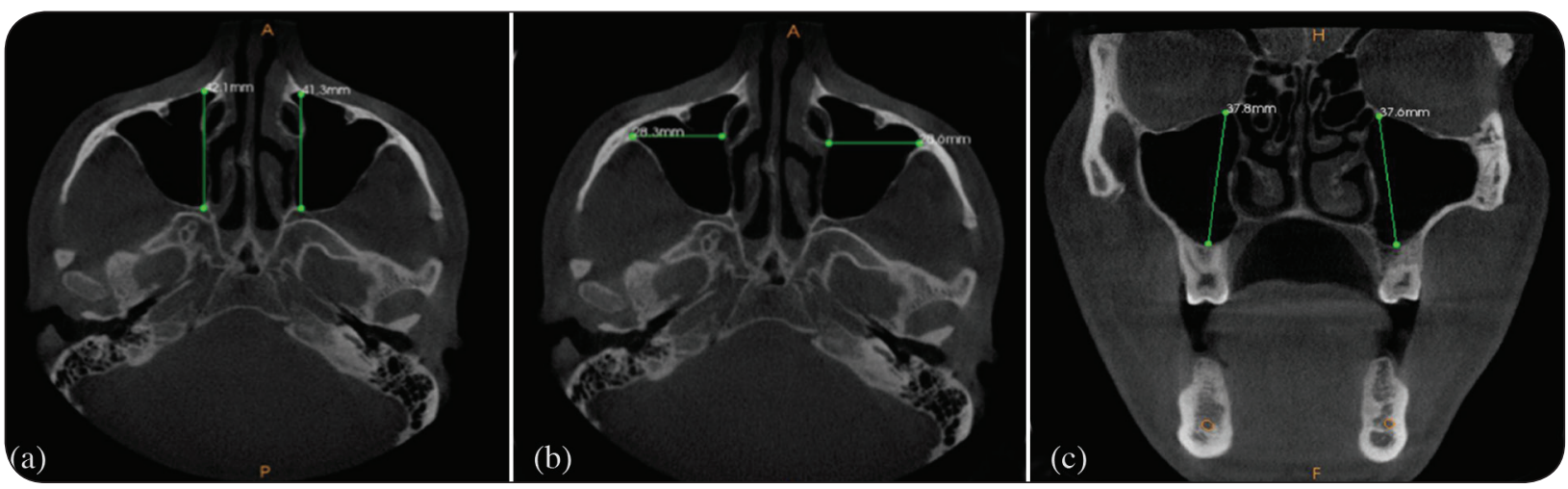

Fig. (1) A: depth of maxillary sinus, B: width of maxillary sinus, C: height of maxillary sinus

values of dimensions between any age group and any another age group. It was difference in mean values of dimensions between right and left sides of maxillary sinus but this difference was not statistically significant.

Table (1): Showing that; higher mean values were recorded in males compared with females. .Right and left height was statistically significant difference in male group than in female group $(\mathrm{p}<0.05)$

Table (1): Illustrating mean $(M) \pm S D$ of the three dimensions in $\mathrm{mm}$ (width, depth, height) of both maxillary sinus in males and females

\begin{tabular}{|c|c|c|c|c|c|}
\hline \multirow{2}{*}{ Dimension } & \multicolumn{2}{|c|}{ Male A } & \multicolumn{2}{c|}{ Female B } & \multirow{2}{*}{ P-value } \\
\cline { 2 - 5 } & $\mathrm{M}$ & $\pm \mathrm{SD}$ & $\mathrm{M}$ & $\pm \mathrm{SD}$ & \\
\hline RT Width & 25.7 & \pm 3.1 & 24.9 & \pm 3.8 & $0.26 \mathrm{NS}$ \\
\hline RT Depth & 32.4 & \pm 2.5 & 31.8 & \pm 3.2 & $0.24 \mathrm{NS}$ \\
\hline RT Height & 35.8 & \pm 4.8 & 30.6 & \pm 4.5 & $<0.0001^{*}$ \\
\hline LT Width & 24.7 & \pm 3.6 & 24.8 & \pm 4.9 & $0.62 \mathrm{NS}$ \\
\hline LT Depth & 31.5 & \pm 3.2 & 31.1 & \pm 3.1 & $0.45 \mathrm{NS}$ \\
\hline LT Height & 37.3 & \pm 4.3 & 30.1 & \pm 3.6 & $<0.0001^{*}$ \\
\hline
\end{tabular}

*Significant $(P<0.05)$ NS:non-significant $(P>0.05)$
Table (2): showing that; there was no statistically significant difference between (group 1) and (group 2) in the mean values of all maxillary sinus dimensions in both sides due to $(\mathrm{P}>0.05)$ in all comparisons, all the remaining comparisons of age groups were revealed the same result due to $(\mathrm{P}>0.05)$ in all the remaining comparisons of age groups.

Table (2): Illustrating mean $(M) \pm S D$ of of the three dimensions in $\mathrm{mm}$ (width, depth, height) of both maxillary sinuses between age groups 1 and 2 .

\begin{tabular}{|l|c|c|c|c|c|}
\hline \multirow{2}{*}{ Dimension } & \multicolumn{2}{|c|}{ Group1 } & \multicolumn{2}{c|}{ Group2 } & \multirow{2}{*}{ P-value } \\
\cline { 2 - 5 } & $\mathrm{M}$ & $\pm \mathrm{SD}$ & $\mathrm{M}$ & $\pm \mathrm{SD}$ & \\
\hline RT Width & 24.8 & \pm 4.5 & 25.1 & \pm 3.9 & $0.38 \mathrm{NS}$ \\
\hline RT Depth & 32.2 & \pm 2.7 & 32.3 & \pm 2.9 & $0.94 \mathrm{NS}$ \\
\hline RT Height & 33.5 & \pm 5.1 & 34.1 & \pm 5.7 & $0.65 \mathrm{NS}$ \\
\hline LT Width & 24.6 & \pm 4.04 & 24.5 & \pm 4 & $0.96 \mathrm{NS}$ \\
\hline LT Depth & 31.4 & \pm 2.1 & 31.6 & \pm 3.6 & $0.79 \mathrm{NS}$ \\
\hline LT Height & 33.2 & \pm 4.1 & 34.6 & \pm 5.8 & $0.23 \mathrm{NS}$ \\
\hline
\end{tabular}

*Significant $(P<0.05)$ NS:non-significant $(P>0.05)$ 


\section{DISCUSSION}

In the present study, the dimensions of maxillary sinus was evaluated by CBCT imaging because this technology has achieved considerable reduction of absorbed radiation doses compared to medical CT imaging and a bit similar to dental panoramic radiography. Field of view limitations have further reduced the effective dose. Standard dental protocol scans using traditional CT delivers 1.5-12.3 times greater radiation than comparable medium field of view dental CBCT scans. . ${ }^{(8)}$

The dimensions of maxillary sinus including depth, width and height were selected to evaluation in the present study due to the clinical significant of maxillary sinus with dental implant placement and bone augmentation. Maxillary sinuses were divided previously into three defined anatomical classes according to sinus depth in to: class I (above the hard palate), class II (0-6 mm below the hard palate) and class III ( $>6 \mathrm{~mm}$ below the hard palate). Maxillary sinus depth is an important anatomical parameter that has to be continuously evaluated by the clinician in the course of preprosthetic treatment planning. Depending upon the sinus class, different treatment regimens may be at disposal: in sinuses belonging to class I, with little sinus depth and only slightly reduced ridge height, dental implants may usually be placed without prior sinus augmentation. This clinically easy class might be expected in a quarter of the patients without the need for sinus augmentation. In sinuses belonging to class II and III, with greater sinus depth and moderately to severely reduced ridge height; sinus augmentation is indicated prior to dental implant placement unless ultra-short implants are being used. Alveolar height was significantly influenced by the sinus class: the average residual ridge height gradually decreased with increasing sinus depth from class I to class III. This can be attributed to the greater extension of the maxillary sinus into the alveolar process, resulting in a reduction of the ridge height. ${ }^{(9)}$
In the present study comparison between human Egyptian males and females within the same age range of maxillary sinus dimensions were performed. Higher mean values were recorded in males compared with females, as the followings: the mean value of the maximum right and left width dimensions of maxillary sinus in male was larger than female but without statistically significant differences. The mean value of right and left depth dimensions of maxillary sinus in male were larger than female with no statistically significant differences. The mean value of right and left height dimensions of maxillary sinus in male were larger than right and left height dimensions of maxillary sinus in female group with statistically significant difference. These finding were in agreement with other results; they concluded that; right and left height of MS in female were found to be smaller than those of male with statistical significant differences. ${ }^{(10)}$

Also the result were in accordance with other findings that revealed the mean of width of maxillary sinus for male was $(24.7 \mathrm{~mm})$ for the right side and $(25.6 \mathrm{~mm})$ for the left side. Female had statistically significant lower values for both right and left sides (22.7 and $23 \mathrm{~mm}$ ), respectively. The mean value length of maxillary sinus for male was $(39.3 \mathrm{~mm})$ for the right side and $(39.4 \mathrm{~mm})$ for the left side which was greater than that recorded for female $(36.9 \mathrm{~mm})$ for the right and $(37 \mathrm{~mm})$ for the left and with statistically significant difference. Also the mean value for the sinus height recorded for male was $(43.3 \mathrm{~mm})$ for the right side and (45.1) for the left side which was significantly greater than that recorded for female $(39.9 \mathrm{~mm})$ for the right side and $(40 ` \mathrm{~mm})$ for the left side. So the maxillary sinus exhibits anatomic variability between genders. A significant sex difference was found in relation to maxillary sinus width, length, and height. Among these parameters, the left maxillary sinus height was the best discriminate variable between genders. ${ }^{(11)}$

The results of present study regarding a higher mean values in maxillary sinuses in males compared 
with females. From physiological point of view two explanations can be offered to explain why males have larger maxillary sinuses dimensions than females the firstly was based on males need to have correspondingly bigger lungs to support their relatively more massive muscles and body organs. ${ }^{(12)}$ The second cause was attributed to the males need a larger airway, which begins with the nose and nasopharynx. In other words, physiological changes in nasal cavity size and shape occur as a direct result of respiration-related needs, such as warming and humidifying inhaled air. As the maxillary sinus occupies the remaining space within the naso-maxillary complex, it also increases in size. ${ }^{(13)}$

On the other hand, the results of the present study were in contrast with other finding: which showed that; female revealed greater values of left MS width than males group which statistically significant. The comparison between male and female groups showed statistically insignificant differences on both the right and left sides with respect to the MS length, height, area, volume and perimeter. However, the female showed statistically significant higher values for left side MS width. ${ }^{(14)}$

In the present study ages of populations subjected to evaluation start from twenty years old and not exceed the fifty years old and were divided into three groups. According to finding of the present study; there was no statistically significant difference between age groups. This results might be explained by two causes, the firstly is due to exclusion any scans that having any extracted tooth in both upper sides to avoid any pneumatization to occur. This result was in parallism with other study which showed that; the individuals images included in his study did not exhibit a proportionate distribution for age, and missing teeth is one of the exclusion criteria; for this reason, varying results can be observed in comparison to other studies. Different results may be related to the different age distributions of the samples and dentition status of the individuals. The alteration in adult maxillary sinus dimensions volume with aging may be related to the loss of maxillary posterior teeth. ${ }^{(15)}$ The second cause was attributed to restriction of sample of population in the present study in age between (2050) years old which in middle age population, the pneumatization of the sinus ends with the complete eruption of the third molars at age of twenty. In addition; over age of 50 year; bone changes begin to occur as in the cortical bone, there was a little amount of Volkmann's and Haversian channels and nearly all osteoblasts were hollow. In the cancellous bone the trabeculae were thin, allowing ample medullary space, frequently engaged by adipocytes and fat cells leading to bone resorption. ${ }^{(16)}$

In a study about age-related morphological changes of the maxillary sinus which performed on 70 cases (36 males and 34 females, mean: 45.4 years) include each ten cases from the second to seventh decade, six cases in the eighth decades and four cases in the ninth decades. They showed that; the poster-anterior, medial-lateral diameters and the area had their peaks in approximately the third to fifth decades. From these results it can be suggested that there is a turning point in the size change of the maxillary sinus around 50 years of age. ${ }^{(17)}$

In contrast to these previous studies which about the age changes of maxillary sinus dimensions there was found another study about morphometric examination of the Para-nasal sinuses and mastoid air cells using computed tomography, which performed on 91 cases (47 men and 44 women) ranged in age from 5 years to 55 years. They concluded that; the volumes and dimensions of the Para-nasal sinuses and volume of mastoid air cells were reported to increase with age. Also the dimensions of Para-nasal sinuses and volumes of mastoid air cells increase regularly with age in both sexes. This contractility could be attributed to wide range of age in the study. ${ }^{(18)}$

Also in the present study regarding comparison between the right and left side of maxillary sinus dimensions (width, depth, height) within the same 
image person revealed that; it was no statistical significant difference between right and left maxillary sinus. The same result were obtained by other a study, they found that; maxillary sinus volume between left and right sides were not statistically significant. ${ }^{(\mathbf{1 9})}$ In addition, measurement of maxillary sinus volume and dimension in correlation to the age and gender a comparative study among individuals with dentate and edentulous maxilla showed that; the mean values of the right and left maxillary sinus volume, width, depth and height showed no significant difference between the right and left side for the four variables if both side were considered together. This study showing that; association of maxillary sinus measurements with the age regarding age grouping, the four variables (volume, width, depth and height) showed significant difference among the three age group, where all of them found to decrease with the age in both dentate and edentulous group. The volume decrease with the age might be related to skeletal size and physique. ${ }^{(20)}$

\section{CONCLUSIONS}

From results of this study, dimensions of maxillary sinus in males were larger than in females with statistically significant difference in height dimension, no statistically significant difference between studied groups regarding the age that may be due to the sample selection was in middle age and due to absence of upper posterior missing teeth, and lastly no statistically significant difference between right and left sides of maxillary sinus dimensions in the same individual image.

\section{REFERENCES}

1. Hamdy RM, Abdel Wahed N. Three Dimensional linear and volumetric analysis of Maxillary sinus pneumatization. J Adv. Res 2014; 5:387-95.

2. Masri AA, Yusof A, Hassan R. A Three dimensional computed tomography (3D-CT): A study of maxillary sinus in Malays. CJBAS. 2013; 1:125-34.
3. Saccucci M, Cipriani F, Carderi S, Di Carlo G, D'Attilio $\mathrm{M}$, Rodolfino D, et al. Gender assessment through threedimensional analysis of maxillary sinuses by means of Cone Beam Computed Tomography. Eur Rev Med Pharmacol Sci, 2015; 19:185-93.

4. Kilic C, Kamburoglu K, Ozen T, Balcioglu HA, Kurt B, Kutoglu T, et al. The Position of the Mandibular canal and Histologic Feature of the Inferior Alveolar Nerve. Clin Anat 2010; 23:34-42.

5. Tambawala SS, Karjodkar FR, Sansare K, Prakash N. Sexual dimorphism of maxillary sinus using cone beam computed tomography. Egyptian J of Forensic Sciences. 2016; 6(2):120-5.

6. Mohlhenrich S. C, Heussen N , Peters F, Steiner T, Holzle $\mathrm{F}$, Modabber A. Is the maxillary sinus really suitable in sex determination? A three-dimensional analysis of maxillary sinus volume and surface depending on sex and dentition. J of Craniofac Sur. 2015: 26(8):723-26.

7. Song SY, Hong JW, Roh TS, Kim YO, Kim DW, Park BY. Volume and distances of the maxillary sinus in craniofacial deformities with mid facial hypoplasia. Otolaryngol Head Neck Surg 2009; 141(5):614-20.

8. Ludlow JB, Ivanovic M. Comparative dosimetry of dental CBCT devices and 64-slice CT for oral and maxillofacial radiology. Oral Surg Oral Med Oral Pathol Oral Radiol Endod J. 2008; 106(1):106-14.

9. Wagner F, Dvorak G, Nemec S, Pietschmann P, Traxler H, Schicho K, et al. Morphometric analysis of sinus depth in the posterior maxilla and proposal of a novel classification. Scientific Reports. 2017; (7):1-7.

10. Amin MF, Hassan EL. Sex identification in Egyptian population using multi detector computed tomography of the maxillary sinus. J of foren and Leg Med. 2012; 19(2):65-9.

11. Uthman AT, AlRawi NH, AlNaaimi AS, AlTimimi JF. Evaluation of maxillary sinus dimensions in gender determination using helical CT scanning. J Forensic Sci. 2011; 56:403-8.

12. Enlow D H. In: Facial Growth. 3rd ed. W.B. Saunders Philadelphia; 1990: pp 6-7.

13. Sharma SK, Jehan M, Kumar A. Measurements of maxillary sinus volume and dimensions by computed tomography scan for gender determination. JASI. 2014; 63(1):36-42. 
14. Urooge A, Patil BA. Sexual dimorphism of maxillary sinus. A morphometric analysis using cone beam computed tomography. JCDR 2017; 11(3):67-70.

15. Gulec M , Tassoker M, Magat G, Lale B , Ozcan S , Orhan $\mathrm{K}$. Three-dimensional volumetric analysis of the maxillary sinus. A cone-beam computed tomography study. Folia Morphologica J .2019; 1-14.

16. ELbaz D. A, El-Shall O, El Kolaly H. sexual dimorphism by analysis of maxillary sinus dimensions in a sample of Egyptian population using cone beam computed tomography. AlAzhar Dent J for Girls. 2019; 6(4): 385-90.

17. Iwai K, Hashimoto K, Kawabe Y, Shinoda, Kudo I.
Age-related changes in maxillary sinus morphology. Geriatric dentistry J.1995; 10(1): 31-41.

18. Karakas S, Kavaklı A. Morphometric examination of the para-nasal sinuses and mastoid air cells using computed tomography. (ASM) Annals of Saudi med. 2005; 25(1): 41-5.

19. Ariji Y, Kuroki T, Moriguchi S, Ariji E, Kanda S. Age changes in the volume of the human maxillary sinus:a study using computed tomography. (DMFR) J.1994; 23(3):163-8.

20. Jasim HH, Al-Taei JA. Computed tomographic measurement of maxillary sinus volume and dimension in correlation to the age and gender (comparative study among individuals with dentate and edentulous maxilla). J Bagh Coll Dent. 2013; 25(1):87-93. 
مجلة أسيوط لطب الأسنان
النشر الرسمي لكلية طب الأسنان جامعة الأزهر أسيوط الكاية

مصر

\section{تقييم ابعاد الجيب الأنفي باستخدام الأشعة المقطعية

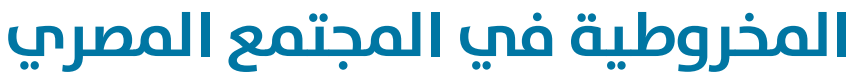

\section{هيثم توفيق حمدى1*، عاصم محمد كامل2، فتحي عبد العظيم ابو زيلد2}

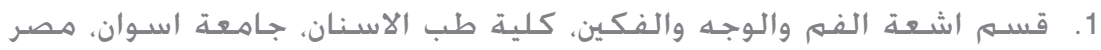

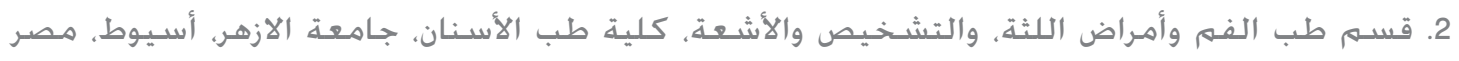
HITHAM TAWFIK.2046@AZHAR.EDU.EG البريد الإلكتروني: *

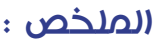

الهدف: تم تصميه هذه الدراسة لتقييم التباين العتمل في أبعاد الجيوب الفكية في السكان المصريين باستخدام الأشعة الخخروطية فيما يتعلق بالعمر والجنس والجمانبين.

المواد والاسـاليب: تم اختيار 120 مقطع اشعاعى مخروطي من الجيوب الفكية الثنائية للهصريين البالغين من كلا الجنسين الذين تتراوح

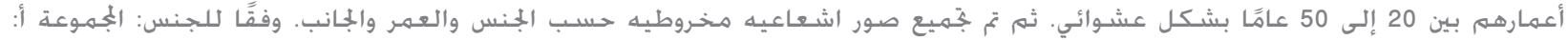

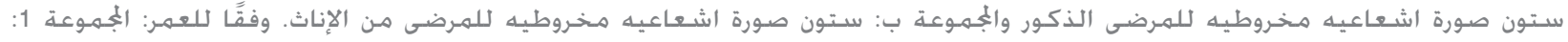

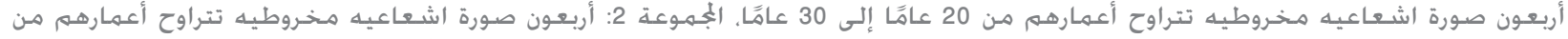

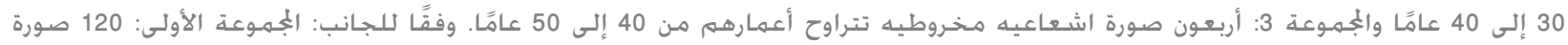

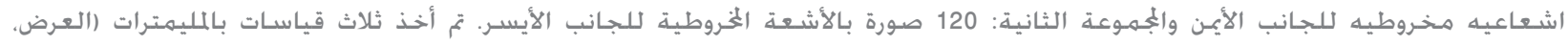

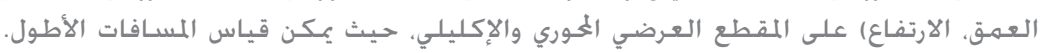

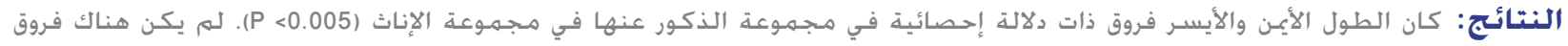

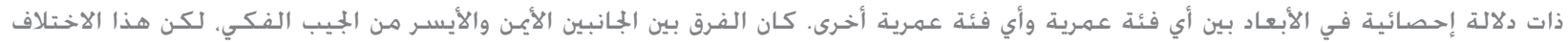
لهم يكن ذا دلالة إحصائية.

الخخلاصة: وجد أن القيم المتوسطة لأبعاد الجيوب الأنفية الفكبة للذكور أكبر من تلك الخاصة بالإناث وكان هذا الاختلاف ذا دلالة إحصائية فقط لأبعاد الارتفاع ألخاع الجيب الأنفي، الأشعة المقطعية الخمروطية، خديد الجنس ، الجمتمع ، مقاطع اشعاعيه. الكلمات المفتاحية المباتية 